also particularly influential'. An example of how socioeconomic status can influence suicide rates is the dramatic rise of suicides in Greece during the ongoing recession in the past few years. Branas and colleagues, examining national data from the Hellenic Statistical Authority over a period of 30 years, assembled monthly counts of all suicides, and found that select austerity-related events in Greece corresponded to statistically significant increases in suicides. January 2002, a time of optimism which saw the launch of the euro in Greece, marked an abrupt but temporary decrease in male suicides. There was then a marked and sustained increase in male suicides in October 2008, when the Greek recession began. In April 2012 there was an abrupt but temporary increase, which, according to the authors, followed a public suicide in response to austerity conditions. Suicide rates in women also showed an abrupt and sustained increase from May 2011 and there was a dramatic increase of $35.8 \%$ in women and $18.5 \%$ in men after the passage of the new austerity measures.

Although not able to claim cause and effect, the authors demonstrate a good correlation between austerity and suicide increase as well as prosperity and suicide decrease. The authors warn those in power who consider future austerity measures to give greater weight to the unintended mental health consequences as well as to the public messaging of these policies and related events.

Branas, C. C., Kastanaki, A. E., Michalodimitrakis, M., et al (2015) The impact of economic austerity and prosperity events on suicide in Greece: a 30-year interrupted time-series analysis. BMJ Open, 5 , e005619, doi: 10.1136/bmjopen-2014-005619.

\section{A global health risk framework (GHRF)}

7 he outbreak of ebola in West Africa high1 lighted the shortcomings of the current global health system, claim the authors of an article in the New England Journal of Medicine. An independent, multinational Commission on a Global Health Risk Framework for the Future has now been established to recommend a more effective global architecture for mitigating the threat of epidemic infectious disease. The Commission will be guided by a sound evidence base and will rigorously analyse options for improving governance, finance, health system resilience, and research and development for global health security. It will aim to foster trust, internationally, with various levels of government, civil society, academia and industry, and to keep the framework from being influenced by politics or the interests of any one country or organisation. The Commission's work will be overseen by an international group. The authors of the article are leading this: Dr Dzau is the chair and Dr Rodin the vice-chair of the International Oversight Group of the Global Health Risk Framework.

This initiative will look into ways of reforming or empowering the WHO and the UN systems so that they respond more effectively to public health emergencies. These could include the development of mechanisms for mobilising a global health workforce, strong regional networks that share information to coordinate responses, and possibly creating national command centres. To ensure cooperation and global support and effects well beyond the health sphere, they plan to feature the Commission's work at major events of the UN, the World Health Assembly and the G7 and G20 groups of countries. They recognise that, ultimately, world leaders' actions will determine international preparedness for future pandemics and medical disasters.

Dzau, V. J. \& Rodin, J. (2015) Creating a global health risk framework. New England Journal of Medicine, 373, 991-993.

\section{What if there were a pill that made us more compassionate?}

$A \mathrm{~s}$ the refugee influx into Europe accelerates $A$ and the drowning of men, women and children continues, the attitudes of many of those at the receiving end are hardening. What if there were a pill to make us more compassionate? Scientists claim there may be. Giving a drug that changes the neurochemical balance of the prefrontal cortex is associated with greater willingness to engage in pro-social behaviours such as ensuring resources are divided more equally.

In a double-blind study, 35 participants, including 18 women, received tolcapone, a drug used in the treatment of Parkinson's disease (it prolongs the effects of dopamine associated with reward and motivation in the prefrontal cortex), or placebo. They were asked to take a simple economic test, which involved dividing money between themselves and an anonymous recipient. When receiving tolcapone, the participants divided the money in a fairer and more egalitarian way than when they received placebo.

The authors suggest that fair-mindedness is not a stable personality trait and it can be affected by targeting specific neurochemical pathways in the brain. Consequently, studying basic scientific questions about human nature might provide insights into the diagnosis and treatment of social dysfunctions.

Sáez, I., Zhu, L., Set, E., et al (2015) Dopamine modulates egalitarian behavior in humans. Current Biology, doi: 10.1016/j. cub.2015.01.071

\section{Forthcoming international events}

6-10 July 2016

World Psychiatric Association International Congress: Integrating Clinical, Community, and Public Health in Psychiatry

Istanbul, Turkey

Website: http://www.wpaistanbul2016.org

18-22 November 2016

World Psychiatric Association International Congress: Psychiatry: Integrative Care for the Community

Cape Town, South Africa

Website http://www.wpacapetown2016.org.za 